\title{
Üniversite Öğrencilerinde Fiziksel Aktivite, Sedanter Süre ve Yaşam Kalitesi İlişkisinin Değerlendirilmesi
}

DOI: 10.26466/opus.532283

*

$\underline{\text { Atakan Yilmaz }}$

*Dr. Öğr. Üyesi, Başkent Üniversitesi, Spor Bilimleri Bölümü, Ankara/Türkiye

E-Posta: atakan@baskent.edu.tr

ORCID: $0000-0002-4520-0220$

Öz

Çalışmanın amacı, üniversite öğrencilerinin fiziksel aktivite (FA) ve sedanter davranış (SD) sürelerini belirleyerek yaşam kaliteleri üzerine etkilerini değerlendirmektir. Çalışmanın evreni Nisan 2018'de Ankara'da bir vakıf üniversitesinin farklı bölümlerinde öğrenim gören lisans öğrencileri olarak belirlenmiş ve rastgele örnekleme yöntemiyle seçilen ve araştırmaya katılmayı kabul eden 400 öğrenci örnekleme dâhil edilmişsir. Anket formu öğrencilerin sosyo-demografik özelliklerini, genel să̆lık durumlarmı ve günlük fiziksel aktivite ve sedanter davranış sürelerini belirlemeye yönelik sorular ile Görsel Analog Skalası'ndan oluşmaktadır. Araştırma verileri tanımlayıcı istatistikler, Mann-Whitney U testi, Kruskal Wallis testi ve Spearman korelasyon katsayısı ile değerlendirilmiştir. Araştırmaya katılan 400 ün-

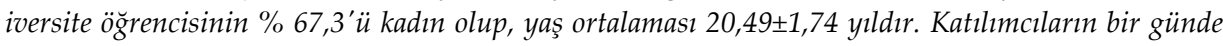
ortalama 2 saat fiziksel olarak aktif olduklarl, ortalama 9 saat sedanter oldukları belirlenmiştir. Katılımcıların yaşam kalitesi puan ortalamaları $65,59 \pm 17,85$ olarak hesaplanmıştır. Üniversite öğrencilerinin yaşam kalitesi puanlarının boş zamanlarında fiziksel aktivite için ayırdıkları süre ile pozitif yönde $(r=0,772, p=0,000)$, sedanter davranışlar için ayırdıkları süre ile negatif yönde $(r=0,772$, $p=0,000)$ istatistiksel olarak anlaml ilişki olduğu belirlenmiştir. Çalışmada üniversite öğrencilerinin fiziksel aktivite sürelerinin sağlıkl bir yaşam için yetersiz olduğu, ekran ve sosyal amaçlı sedanter davranışlarına ayırdıkları sürelerin azaltılmasının önemli olduğu olacă̆ı sonucuna ulaşılmıştır.

Anahtar Kelimeler: Fiziksel Aktivite, Sedanter Davranış, Üniversite Öğrencileri, Yaşam Kalitesi 


\title{
Physical Activity, Sedantery Behaviour and Quality of Life among University Students
}

\begin{abstract}
The aim of this study was to evaluate the effects of physical activity (PA) and sedentary behavior (SB) on the quality of life of university students. The sample of the study was determined as undergraduate students in different departments of a foundation university in Ankara in April 2018 and 400 students were selected by random sampling method and accepted to participate in the study. The questionnaire consisted of the questions related to the socio-demographic characteristics, general health status and daily physical activity and sedentary behavior of the students and the Visual Analogue Scale. Research data were evaluated by descriptive statistics, Mann-Whitney $U$ test, Kruskal Wallis test and Spearman's correlation coefficient. Of the 400 university students surveyed, $67.3 \%$ were women, with a mean age of $20.49 \pm 1.74$ years. It was determined that the participants were physically active for 2 hours in a day and they were sedentary for an average of 9 hours. Quality of life scores of the participants were calculated as $65,59 \pm 17,85$. There was a statistically significant relationship between the quality of life scores of the university students and the duration of physically active $(r=0,772, p=0,000)$, and the duration of sedentary behaviors $(r=0,772, p=0,000)$. In this study, it was concluded that the duration of physical activity of university students is insufficient for a healthy life, it is important to reduce the time spent for sedentary behaviors especially for screening and social activities.
\end{abstract}

Keywords: Physical activity, quality of life, sedentary behavior, university students

OPUS (c) Uluslararası Toplum Araştırmaları Dergisi-International Journal of Society Researches ISSN:2528-9527 E-ISSN : 2528-9535

http://opusjournal.net 


\section{Giriş}

Fiziksel aktivite, istirahat düzeyinin üzerinde enerji harcaması içeren her türlü kas kasılması sonucu oluşan hareket olarak tanımlanır (Caspersen, Powell ve Christenson, 1985). Dünya Sağl1k Örgütü'nün verilerine göre fiziksel hareketsizlik (fiziksel aktivite eksikliği), küresel ölüm nedenleri arasında dördüncü önemli risk faktörü olarak belirlenmiştir. Fiziksel hareketsizliğin gögüus ve kolon kanserlerinin \% 21-25'inin, tip 2 diyabet hastalığının \% 27'sinin ve iskemik kalp hastalığının \% 30'unun ana nedeni olduğu tahmin edilmektedir (World Health Organization, 2018). Son zamanlarda fiziksel aktiviteye paralel olarak sedanter davranışlar da, bireylerin fiziksel aktivite düzeylerinden bağımsız olarak, sağlığın önemli bir belirleyicisi olarak daha fazla kabul görmektedir (Owen, Healy, Matthews ve Dunstan, 2010; Biswas ve diğ., 2015; Omorou ve diğ., 2016). Sedanter davranış, uyanık halde, yatar ya da oturur pozisyonda 1,5 MET (Metabolik Eşdeğer) ve bunun altında seviyede enerji tüketimine yol açan herhangi bir aktivite olarak tanımlanmıştır (Sedentary Behaviour Research Network, 2012; Tremblay ve diğ., 2017). Yüksek sedanter davranışın tüm nedenlere bağlı mortalite, kardiyovasküler hastalık, kanser ve diyabet kaynaklı mortalite ve insidans riskleri ile ilişkili olduğu bulunmuştur (Owen, Healy, Matthews ve Dunstan, 2010; Biswas ve diğ., 2015; Omorou ve diğ., 2016; Tremblay ve diğ., 2017; Wu, Han, Zhang, Luo, Hu ve Sun, 2017; Cabanas-Sánchez, Martínez-Gómez, Esteban-Cornejo, Castro-Piñero, Conde-Caveda ve Veiga, 2018). Yapılan araştırmalar hem fiziksel aktivitenin hem de sedanter davranışın, genel ve hasta popülâsyonlarda sağlıkla ilgili yaşam kalitesi ile ilişkili olduğunu, fiziksel aktivitenin sağlıkla ilgili yaşam kalitesi ile pozitif bir şekilde ilişkiliyken, sedanter davranışın düşük sağlıkla ilgili yaşam kalitesi ile ilişkili olduğunu ortaya koymuştur (Wu ve diğ., 2017; George ve diğ., 2014; Taricco ve diğ., 2014; Vagetti ve diğ., 2014; Meneguci ve diğ., 2015).

Sağlık Bakanlığı tarafından 2015 yılında yapılan bir araştırmada, Türkiye'de kadınların \%13'ünün, erkeklerin ise \%23'ünün yeterli düzeyde fiziksel aktivite yaptığı belirlenmiştir (Sağlık Bakanlığı, 2015). Kadınlarda ve erkeklerde hiç egzersiz yapmayanların oranı yaşla birlikte artış göstermektedir (Sağlık Bakanlığı, 2015). Bu artışın en belirgin görüldüğü yaş grupları ise geç ergenlik dönemi, lise sonrası ile üniversite yıllarıdır 
(Cengiz, İnce ve Çiçek, 2009; Deliens, Deforche, De Bourdeaudhuij ve Clarys, 2015; Peterson, Sirard, Kulbok, DeBoer ve Erickson, 2018). Gençlikten yetişkinliğe geçiş dönemi olarak ifade edilen 18-25 yaş arası, bir diğer deyişle üniversite dönemi, hem sağlıkla ilgili alışkanlıklarda bozulma ile nitelendirilen bir dönem olduğu için (Peterson ve diğ., 2018; Joseph, Royse, Benitez ve Pekmezi, 2014; Clemente, Martins, Nikolaidis veMendes, 2017) hem de bu dönemde benimsenen düzenli fiziksel aktivitenin ilerleyen yaşlarda sağlık faydalarına dönüşmesi öngörüldüğü için (Malina, 2001; Fernandes ve Zanesco, 2010; Omorou, Langlois, Lecomte, Briançon ve Vuillemin, 2016) kritik dönem olarak kabul edilmektedir. Uluslararası yazında, düzenli fiziksel aktivite yapma ve sedanter süreyi kısaltma ile önemli düzeyde fiziksel ve zihinsel sağlık faydası sağlanacağına ilişkin tutarlı epidemiyolojik kanıtlar mevcuttur (Wu ve diğ., 2017; Omorou ve diğg., 2016; Kolt ve diğ., 2017; Balboa-Castillo ve diğ., 2011; Herman, Hopman ve Sabiston, 2015; Guallar-Castillón ve diğ., 2014; Lindsay ve diğg., 2016). Ancak Türkiye'de yapılan araştırmaların sadece fiziksel aktivite ve yaşam kalitesi ilişkisine odaklandığ 1 görülmektedir (Tekkanat, 2008; Ergül ve Çamlıyer, 2017; Tözün, Sözmen ve Babaoğlu, 2017; Lapa ve Korkmaz, 2017; Sağlam ve Yılmaz, 2017; Eruzun, 2017; Özdemir, Özşaker ve Ersöz, 2016). Bu çalışmanın amacı Ankara'da bir vakıf üniversitesinde öğrenim gören üniversite öğrencilerinin fiziksel aktivite ve sedanter davranış sürelerinin belirlenerek, yaşam kaliteleri ile ilişkilerinin değerlendirilmesidir. Çalışmanın özellikle 18-25 yaş grubu başta olmak üzere, Türkiye'de fiziksel aktiviteyi artırmaya ve sedanter davranışları azaltmaya yönelik yapılacak kapsamlı çalışmalar için en önemli müdahale alanlarını ortaya koyması hedeflenmiştir.

\section{Materyal ve Metod}

\section{Araştırmanın Evreni ve Örneklemi}

Kesitsel tipteki araştırma, 2018 yılı Nisan ayında Ankara'da bir vakıf üniversitesinin farklı bölümlerinde öğrenim gören üniversite öğrencileri ile gerçekleştirilmiştir. 
Araştırmanın evrenini Ankara'da bir vakıf üniversitesinde kayıtlı yaklaşık 9.580 lisans öğrencisi oluşturmaktadır. Araştırmanın örneklem büyüklügü \%80 güç için, $\% 50$ oranında, $\% 90$ güven düzeyinde ve $\% 5$ etki büyüklüğü dikkate alınarak 405 lisans öğrencisi olarak belirlenmiştir. Fakültelere göre ulaşılması gereken öğrenci sayısı tabakalı örnekleme yöntemi kullanılarak belirlenmiştir. Örneklemde yer alan 405 öğrenci, tabakalara göre her bir fakülteden, kolayda örnekleme ile seçilmiştir.

\section{Veri Toplama Aracı}

Araştırmada öğrencilere dört bölümden oluşan anket formu uygulanmıştır. İlk bölümde sosyo-demografik bilgiler (yaş, cinsiyet, kimlerle yaşandığı, ailenin aylık geliri, vb.), genel sağlık değerlendirmesi (boy, kilo, genel sağlık değerlendirmesi) ve sağlık davranışları (sigara ve alkol kullanımı, günlük uyku süresi) ile ilgili 12 soru yer almaktadır. İkinci bölümde Sağlıkla İlişkili Yaşam Kalitesi'ni değerlendirmek amacıyla; katılımcıların bugünkü sağlık durumlarına 0-100 arasında bir değer verdikleri ve bunu termometre benzeri bir ölçek üzerinde işaretledikleri Görsel Analog Skalası bulunmaktadır (Ravens-Sieberer ve diğ., 2010). Ölçekten 0 ile 100 arasında değişen yaşam kalitesi skorları elde edilmektedir. Anket formunun üçüncü ve dördüncü bölümü araştırmacılar tarafından literatür araştırmasına dayanarak hazırlanmış olup; üçüncü bölümde üniversite öğrencilerinin fiziksel aktivite için günlük harcadıkları süreyi belirlemeye yönelik dört soru (Tablo 2), dördüncü bölümde ise öğrencilerin sedanter davranışlar için ortalama geçirdikleri günlük süreyi belirlemeye yönelik 12 soru (Tablo 3) yer almaktadır. Katılımcıların fiziksel aktivite ve sedanter davranış sürelerini gerçeğe uyarlamak için ilk olarak uyku ve ders saatleri dişında kalan toplam boş zamanları hesaplanmıştır. $\mathrm{Bu}$ hesaplama için Günlük Süreden Uyku Süresi ve Ders Süresi çıkarılmıştır. İkinci olarak katılımcıların günlük toplam fiziksel aktivite ve sedanter davranış süreleri ayrı ayrı ifadelere verilen yanıtların toplamları ile hesaplanmıştır. Katılımcıların uyarlanmış aktivite/davranış süreleri ise beyan ettikleri davranış süresi ile hesaplanan toplam boş zaman çarpımının her bir davranış süresinin kareleri toplamına oranlanmasıyla hesaplanmıştır (Cabanas-Sánchez, 2018). 


\section{Verilerin Analizi}

Verilerin istatistiksel analizi SPSS 18.0 paket programında gerçekleştirilmiştir. Çalışmanın bağımlı değişkeni olarak Sağlıkla İlişkili Yaşam Kalitesi puanı ele alınmıştır. Çalışmanın bağımsız değişkenleri ise sosyo-demografik özellikler, sağlık davranışları, fiziksel aktiviteye ayrılan süre ve sedanter davranışlar için ayrılan süre olarak kabul edilmiştir. Çalışmanın tanımlayıcı istatistikleri frekans, yüzde ve ortalama \pm standart sapma şeklinde gösterilmiştir. Puanların ve yüzdelerin normal dağılıma uygunluğu Kolmogorov-Smirnov testi ile değerlendirilmiştir. Katılımcıların bir günde fiziksel olarak aktif oldukları süreyi etkileyen sosyo-demografik özellikleri ve sağlık davranışlarını belirlemek üzere Mann-Whitney U testi ve Kruskal Wallis testi yapılmıştır. Katılımcıların yaşam kalitesi puanı ile bir günde ortalama fiziksel aktivite ve sedanter davranış süreleri arasındaki ilişkileri belirlemek üzere Spearman korelasyon katsayısı hesaplanmıştır. Analizlerde istatistiksel anlamlılık $\mathrm{p}<0,05$ olarak kabul edilmiştir. Verilerin analizi aşamasında anket formunu tam olarak doldurmayan 5 katılımcının verileri kapsam dışında bırakılarak, 400 öğrenciye ait veriler analiz edilmiştir.

\section{Bulgular}

Çalışmaya katılan 400 üniversite öğrencisinin yaşları 18 ile 25 arasında

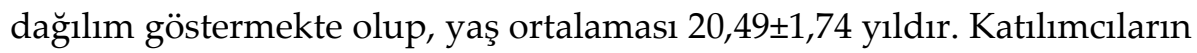
\%67,3'ü kadındır. Katılımcıların \%71,5'i çekirdek aile ile yaşadığını, $\% 60,8$ 'inin aile gelirinin 5.332 TL'nin üzerinde olduğu, \%74,5'inin yaşantısının büyük ölçüde şehir merkezinde geçtiği belirlenmiştir (Tablo $1)$. 
Üniversite Öğrencilerinde Fiziksel Aktivite, Sedanter Süre ve Yaşam Kalitesi İlişkisinin Değerlendirilmesi

Tablo 1. Katılımcılarn Sosyo-Demografik Özelliklerine ve Ortalama Fiziksel Aktivite Yüzdelerine Göre Dă̆ılımı

\begin{tabular}{|c|c|c|c|c|}
\hline \multirow{3}{*}{ Bölüm* } & \multicolumn{2}{|c|}{ Toplam } & \multicolumn{2}{|c|}{ Fiziksel aktivite (\%) } \\
\hline & \multirow[t]{2}{*}{ Sayı } & \multirow[t]{2}{*}{ Yüzde } & \multirow[t]{2}{*}{ Ortalama $\pm S S$} & \multirow[t]{2}{*}{ p } \\
\hline & & & & \\
\hline Sağlık & 159 & 39,8 & $16,22 \pm 13,62$ & \multirow{2}{*}{0,183} \\
\hline Sağlık dişı & 241 & 60,3 & $18,11 \pm 14,04$ & \\
\hline \multicolumn{5}{|l|}{ Cinsiyet } \\
\hline Kadın & 269 & 67,3 & $14,52 \pm 12,27$ & \multirow{2}{*}{$0,000^{* *}$} \\
\hline Erkek & 131 & 32,8 & $23,18 \pm 15,19$ & \\
\hline \multicolumn{5}{|l|}{ Kiminle yaşıyor } \\
\hline Çekirdek aile & 286 & 71,5 & $18,42 \pm 14,46$ & \multirow{2}{*}{$0,015^{* *}$} \\
\hline Diğer & 114 & 28,5 & $14,68 \pm 11,98$ & \\
\hline \multicolumn{5}{|l|}{ Aile geliri } \\
\hline$<5.332 \mathrm{TL}$ & 157 & 39,3 & $16,55 \pm 14,36$ & \multirow{2}{*}{0,342} \\
\hline$\geq 5.332 \mathrm{TL}$ & 243 & 60,8 & $17,90 \pm 13,56$ & \\
\hline \multicolumn{5}{|c|}{ Yaşantının çoğunluğunun geçtiği yer } \\
\hline Küçük yerleşim yeri & 102 & 25,5 & $16,81 \pm 14,37$ & \multirow{2}{*}{0,782} \\
\hline Şehir merkezi & 298 & 74,5 & $17,42 \pm 13,84$ & \\
\hline \multicolumn{5}{|l|}{ BK $\dot{I}^{*}$} \\
\hline Zayıf & 56 & 14,0 & $13,60 \pm 11,93$ & \multirow{3}{*}{$0,002^{* *}$} \\
\hline Normal & 273 & 68,3 & $16,95 \pm 13,37$ & \\
\hline Kilolu & 71 & 17,8 & $21,96 \pm 16,13$ & \\
\hline \multicolumn{5}{|l|}{ GSD $^{*}$} \\
\hline İyi & 320 & 80,0 & $17,68 \pm 14,23$ & \multirow{2}{*}{0,318} \\
\hline İyi değil & 80 & 20,0 & $15,89 \pm 12,23$ & \\
\hline \multicolumn{5}{|l|}{ SİGARA } \\
\hline Evet & 213 & 53,3 & $18,72 \pm 14,23$ & \multirow{2}{*}{$0,041^{* *}$} \\
\hline Hayır & 187 & 46,8 & $15,89 \pm 13,40$ & \\
\hline \multicolumn{5}{|l|}{ ALKOL $^{*}$} \\
\hline Yok & 303 & 75,8 & $17,08 \pm 14,53$ & \multirow{2}{*}{0,622} \\
\hline Aşırı & 97 & 24,3 & $17,78 \pm 12,85$ & \\
\hline \multicolumn{5}{|l|}{ UYKU* } \\
\hline$<7$ Saat & 99 & 24,8 & $16,86 \pm 13,05$ & \multirow{2}{*}{0,684} \\
\hline$\geq 7$ Saat & 301 & 75,3 & $17,52 \pm 14,17$ & \\
\hline TOPLAM & 400 & 100,0 & & \\
\hline
\end{tabular}

${ }^{* *} p<0,05$

* Sinıflamalar:

Bölüm: Öğrencilere açık uçlu sorulan Fakülte ve Bölüm soruları, sağlıkla ilgili bölümler (Sağlık Bilimleri Fakültesi bünyesindeki bölümler, Tip Fakültesi, Diş Hekimliği Fakültesi) ve sağllk dışı bölümler (Ĕ̆itim Fakültesi, Hukuk Fakültesi, Fen Edebiyat Fakültesi, İletişim Fakültesi vb. bünyesindeki bölümler) olarak ikiye ayrılmıştır. Aile geliri: TÜIK Mart 2018 verilerine göre yoksulluk sınırının altı ve üstü iki grup olarak değerlendirilmiştir. BKİ (Beden Kütle İndeksi): Öğrencilere açık uçlu olarak sorulan ağırlık ve boy uzunluğu verilerinden ağırlığın boy uzunluğunun (metre cinsinden) karesine bölünmesiyle hesaplanmıştır. BKİ 18,5'den az olanlar "zayıf", 18,5-24,9 arasinda olanlar "normal" ve 25'den fazla olanlar kilolu olarak sınıflandırılmıştır. Genel sağlık durumu değerlendirmesi 5 'li likert ölçeğinde yapılmış 
olup, "mükemmel", "çok iyi" ve "iyi" değerlendirmeler "iyi", "orta" ve "kötü" değerlendirmeler ise "iyi değil" olarak yeniden gruplandırılmıştır. Aşırı alkol tïketimi: "Alkol kullanıyor musunuz?" ve cevap evet ise "Alkol aldiğını zamanlarda ne kadar tüketirsiniz?" sorular ile belirlenmiştir. Erkekler için haftada birkaç gün 2 bardaktan fazla, kadınlar için haftada birkaç gün 1 bardaktan fazla alkol tüketimi "aşırı" olarak değerlendirilmiştir. Uyku: Katıllmolların yeterli uyuyup uyumadıkları "Bir günde ortalama kaç saat uyuyorsunuz?" sorusu ile belirlenmiş ve 7 ve daha fazla uyku saati "ideal" olarak tanımlanmıştır.

Öğrencilerin bir günde girdikleri ders saatleri 0 saat ile 8 saat arasında dağılım göstermekte olup ortalama 5,21 $\pm 1,53$ saat olarak belirlenmiştir (312,90 $\pm 92,36$ dakika). Öğrencilerin bir günde 3 saat ile 15 saat arasında uyudukları, ortalama olarak $7,36 \pm 1,48$ saat uyudukları belirlenmiştir $(441,60 \pm 89,316)$. Tablo 2 ' de öğrencilerin fiziksel aktivite için ayırdıkları ortalama süreler (dakika olarak) yer almaktadır.

Tablo 2. Katılımcılarn Ortalama Fiziksel Aktivite süreleri

\begin{tabular}{lcccc}
\hline & \multicolumn{2}{c}{$\begin{array}{c}\text { Öğrencilerin bild- } \\
\text { irdikleri FA sü- } \\
\text { resi (dk) }\end{array}$} & $\begin{array}{c}\text { Gerçeğe Uyar- } \\
\text { lanan FA süresi } \\
\text { (dk) }\end{array}$ \\
\hline & $\begin{array}{c}\text { Ortala } \\
\text { ma }\end{array}$ & SS & $\begin{array}{c}\text { Ortala } \\
\text { ma }\end{array}$ & SS \\
\hline Fiziksel aktivite veya spor/egzersiz yapmak & 63,08 & 70,62 & 24,56 & 41,06 \\
$\begin{array}{l}\text { Dişarı çıkmak (yürüyüş, alı̧̧veriş, dans } \\
\text { etme gibi) }\end{array}$ & 121,88 & 83,12 & 64,99 & 73,42 \\
$\begin{array}{l}\text { Hobilerle uğraşmak (evcil hayvan bakımı, } \\
\text { bir müzik aleti çalma, dart oynama gibi) }\end{array}$ & 52,27 & 47,36 & 16,52 & 23,00 \\
$\begin{array}{l}\text { Fiziksel aktivite içeren oyun konsolları (Wii, } \\
\text { Xbox kinect veya benzer) }\end{array}$ & 36,62 & 69,29 & 14,02 & 34,41 \\
\hline Toplam & $\mathbf{2 7 3 , 8 6}$ & $\mathbf{1 7 2 , 3}$ & $\mathbf{1 2 0 , 1 1}$ & $\mathbf{1 0 2 , 3 9}$ \\
\hline Yüzde (\%) & $\mathbf{1 8 , 9 9}$ & $\mathbf{9 , 4 6}$ & $\mathbf{1 7 , 3 6}$ & $\mathbf{1 3 , 8 9}$ \\
\hline
\end{tabular}

Katılımcıların gerçeğe uyarlanmış fiziksel aktivite süreleri incelendiğinde, bir günde ortalama $2,00 \pm 1,70$ saat $(120,11 \pm 102,39$ dakika), boş zamanlarının \%17,36'sı fiziksel olarak aktif oldukları belirlenmiştir (Tablo 2). Erkeklerin, çekirdek aileleri ile yaşayanların, BKİ zayıf olanların ve sigara içmeyenlerin boş zamanlarında daha fazla fiziksel olarak aktif oldukları belirlenmiştir. $(\mathrm{p}<0,05)$ (Tablo 1). Tablo 3'de öğrencilerin sedanter davranışlar için ayırdıkları ortalama süreler (dakika olarak) yer almaktadır. 
Üniversite Öğrencilerinde Fiziksel Aktivite, Sedanter Süre ve Yaşam Kalitesi İlişkisinin Değerlendirilmesi

Tablo 3. Katılımcıların Ortalama Sedanter Davranış Süreleri

\begin{tabular}{|c|c|c|c|c|}
\hline & \multicolumn{2}{|c|}{$\begin{array}{l}\text { Öğrencilerin bild- } \\
\text { irdikleri SD süresi }\end{array}$} & \multicolumn{2}{|c|}{$\begin{array}{c}\text { Gerçeğe Uyarlanan SD } \\
\text { süresi }\end{array}$} \\
\hline & Ortalama & SS & Ortalama & SS \\
\hline TV/Video//DVD İzlemek & 122,34 & 80,78 & 61,51 & 60,80 \\
\hline $\begin{array}{l}\text { Bilgisayar / video oyunları oynamak (Wii, } \\
\text { Xbox kinect veya benzeri oyunlar hariç) }\end{array}$ & 56,87 & 83,28 & 25,43 & 49,99 \\
\hline $\begin{array}{l}\text { Eğlenme amaçlı internet sörfü (www, } \\
\text { sohbet, Facebok gibi) }\end{array}$ & 154,67 & 97,09 & 91,73 & 79,01 \\
\hline Ekran & 333,88 & 186,96 & 178,68 & 114,78 \\
\hline Ekran \% & 28,67 & 11,47 & 31,52 & 18,16 \\
\hline Ödev yapmak/ders çalışmak (bilgisayarsız) & 88,60 & 82,12 & 48,93 & 75,39 \\
\hline Bilgisayarda ödev yapma/ders çalışmak & 72,09 & 74,51 & 33,50 & 59,17 \\
\hline Kitap okumak & 60,97 & 68,40 & 25,98 & 46,32 \\
\hline Eğitim & 221,67 & 157,21 & 108,43 & 118,51 \\
\hline Eğitim \% & 19,91 & 12,65 & 18,93 & 18,81 \\
\hline $\begin{array}{l}\text { Aile veya arkadaşlarla oturmak/ ko- } \\
\text { nuşmak }\end{array}$ & 168,21 & 85,64 & 107,13 & 82,65 \\
\hline $\begin{array}{l}\text { Telefonda konuşmak veya mesaj gönder- } \\
\text { mek, whatsapp vb. }\end{array}$ & 103,06 & 48,26 & 42,12 & 34,18 \\
\hline $\begin{array}{l}\text { Müzik dinlemek (başka bir şey yap- } \\
\text { madan) }\end{array}$ & 73,10 & 51,80 & 24,21 & 26,41 \\
\hline Sosyal & 344,38 & 135,44 & 173,47 & 97,84 \\
\hline Sosyal \% & 30,53 & 9,29 & 30,99 & 16,02 \\
\hline Dinlenmek için oturmak & 120,58 & 92,04 & 64,15 & 68,67 \\
\hline $\begin{array}{l}\text { Bilişsel hobilerle uğraşmak (bulmaca } \\
\text { çözmek, oyun kâğıdı ile oynamak, puzzle } \\
\text { yapmak vb.) }\end{array}$ & 29,83 & 39,12 & 7,40 & 13,97 \\
\hline $\begin{array}{l}\text { Motorlu araçlarla ulaşım (araba, otobüs, } \\
\text { tren, metro veya motosiklet) }\end{array}$ & 88,06 & 45,52 & 33,22 & 33,21 \\
\hline Diğer & 238,49 & 124,59 & 104,78 & 78,79 \\
\hline Diğer \% & 20,87 & 8,35 & 18,53 & 13,30 \\
\hline Toplam & 1138,45 & 381,76 & 565,38 & 136,99 \\
\hline Yüzde & 81,00 & 9,46 & 82,63 & 13,89 \\
\hline
\end{tabular}

Katılımcıların gerçeğe uyarlanmış sedanter davranış süreleri incelendiğinde bir günde ortalama 9,42 $\pm 2,28$ saat (565,38 $\pm 136,99$ dakika), boş zamanlarının \%82,63'ü sedanter oldukları belirlenmiştir (Tablo 3). Katılımcıların sedanter davranış dağılımları incelendiğinde; \%31,6 ekran, $\% 30,6$ sosyal, \%19,1 eğitim ve \%18,5 diğer amaçlarla sedanter davranışlarda bulundukları anlaşılmıştır. Katılımcıların Sağlıkla İlişkili Yaşam Kalitesi puanları 0 ile 100 arasında dağılım göstermekte olup

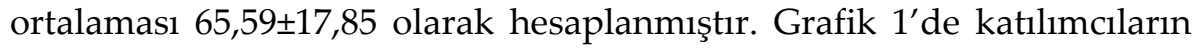


yaşam kalitesi puanları ile boş zamanlarında fiziksel aktiviteye ayırdıkları süre arasındaki ilişki gösterilmektedir.

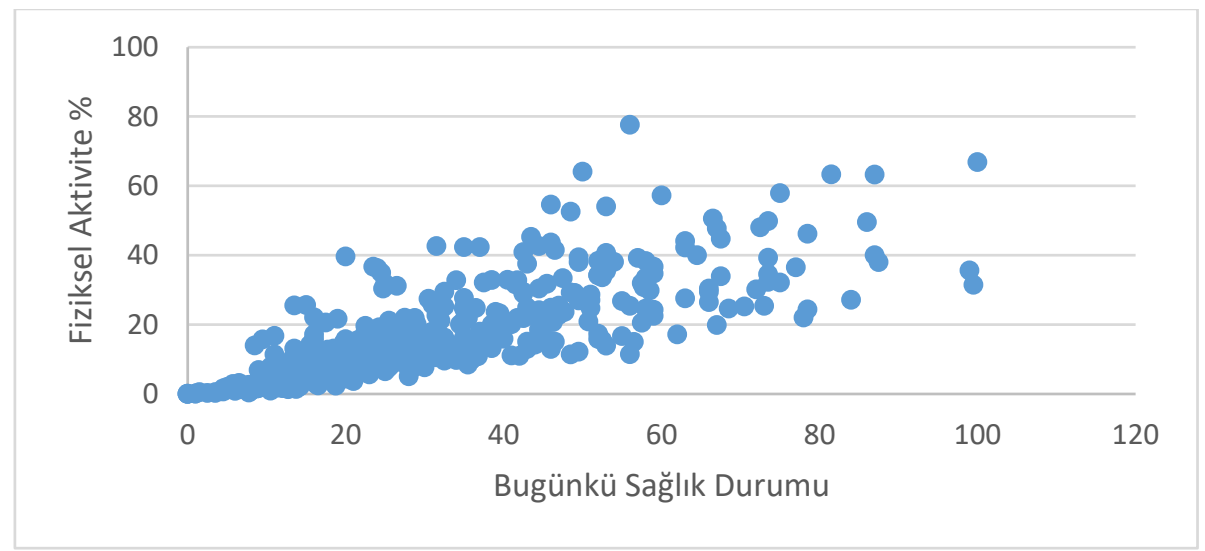

Grafik 1. Yaşam Kalitesi Puanları ile Fiziksel Aktivite Süresi İlişkisi

Spearman sıra farkları korelasyon katsayısı ile değerlendirilen fiziksel aktivite yüzdeleri ile yaşam kalitesi puanı arasında pozitif yönde yüksek düzeyde istatistiksel olarak anlamlı ilişki bulunmuştur $(r=0,772, p=0,000)$. Grafik 2' de katılımcıların yaşam kalitesi puanları ile boş zamanlarında sedanter davranışlara ayırdıkları süre arasındaki ilişki gösterilmektedir.

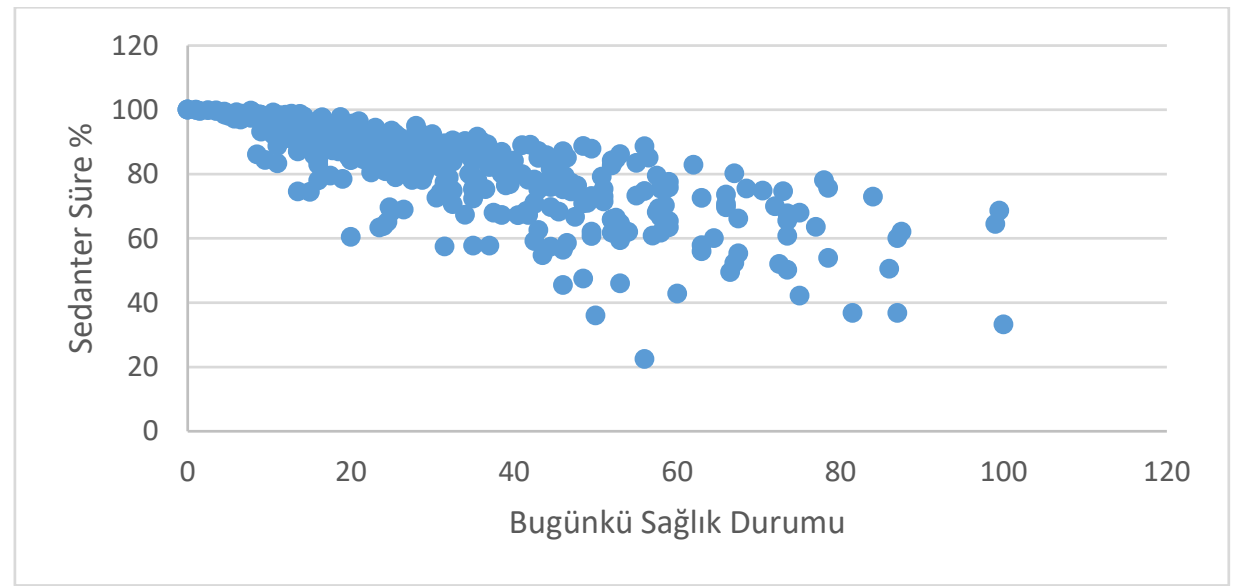

Grafik 2. Yaşam Kalitesi Puanları ile Sedanter Davranış Süresi İlişkisi 
Spearman korelasyon katsayısı ile değerlendirilen sedanter süre yüzdeleri ile yaşam kalitesi puanı arasında negatif yönde yüksek düzeyde istatistiksel olarak anlamlı ilişki bulunmuştur $(r=-0,735, p=0,000)$.

\section{Tartışma}

Üniversite öğrencilerinde, fiziksel aktivite ve sedanter davranışlar için ayırdıkları süreleri ve yaşam kalitesi üzerine etkilerini belirlemek amacıyla yapılan bu çalışmada; Ankara'da bir vakıf üniversitesinde kolayda örnekleme yöntemiyle seçilen 18-25 yaş arası üniversite öğrencilerinin boş zamanlarında fiziksel aktivite ve sedanter davranış süreleri ve yaşam kaliteleri incelenmiştir. Araştırmaya katılan 400 öğrenci bir günde ortalama 2 saat ile zamanlarının \%17'sini fiziksel olarak aktif geçirirken, ortalama 9 saat ile zamanlarının \%82'sini sedanter davranışlar ile geçirmektedir. Ulusal yazında, üniversite öğrencilerinin zamanlarının ne kadarını fiziksel olarak aktif, ne kadarını sedanter olarak geçirdiklerini inceleyen bir çalışmaya rastlanmamakla birlikte, çalışma sonuçları üniversite öğrencilerinde fiziksel aktivite düzeyinin belirlenmesine yönelik yapılan çalışmaların (Cengiz ve diğ., 2009; Tekkanat, 2008; Tözün ve diğ., 2017; Lapa ve Korkmaz, 2017) sonuçları ile uyumludur.

Üniversite öğrencilerinin sedanter davranış dağılımları incelendiğinde, birinci sırada \%31 ile ekran karşısında, ikinci sırada \%30 ile sosyal amaçlı sedanter davranışları olduğu belirlenmiştir. Çalışmanın bu sonucunun üniversite öğrencilerinin ekran bağımlığı, internet bağımlılığı ve telefon bağımlılığı üzerine yapılan araştırmalar ile uyumlu olduğunu söylemek mümkündür (Sabbağ ve Aksoy, 2011; Noyan, Enez Darçın, Nurmedov, Yılmaz ve Dilbaz, 2015; Aslan ve Yazıcı, 2016; Çavuş, Ayhan ve Tuncer, 2016; Kuyucu, 2017).

Çalışmada üniversite öğrencilerinin fiziksel aktiviteye ayırdıkları süreyi etkileyen faktörlere bakıldığında erkeklerin, çekirdek ailesiyle birlikte yaşayanların, vücut kütle indeksi düşük olanların ve sigara kullanmayanların fiziksel olarak daha aktif oldukları belirlenmiştir. Daha önce yapılan araştırmalarda da erkeklerin kadınlara göre daha aktif olduğu (Cengiz ve diğ., 2009; Joseph ve diğ., 2014; Clemente ve diğ., 2017; Lapa ve Korkmaz, 
2017), sağlıklı yaşam tarzı alışkanlıklarını benimseme ve vücut kütle indeksi ile fiziksel aktivite arasında pozitif ilişki olduğu (Tözün ve diğ., 2017; Nelson ve diğ., 2014) sonucuna ulaşılmıştır.

Çalışmada son olarak üniversite öğrencilerinin fiziksel aktivite ve sedanter davranış süreleri ile yaşam kalitesi arasında anlamlı ilişki olduğu belirlenmiştir. Çalışmanın bu sonucu Türkiye'de üniversite öğrencilerinde yapılan fiziksel aktivite yaşam kalitesi ilişkisini değerlendirmeye yönelik çalışmalarla (Eruzun, 2017; Özdemir ve dĭğ., 2016; Çiçek, 2018), Dünyanın farklı ülkelerinde fiziksel aktivite, sedanter davranış ve yaşam kalitesi ilişkisinin değerlendirildiği çalışmalarla (Omorou ve diğ., 2016; Wu ve diğ., 2017; Guallar-Castillón ve diğ., 2014) büyük ölçüde uyumludur.

Araştırmanın bir takım sınırlılıkları vardır. İlk olarak, araştırmanın kesitsel bir saha çalışması olarak planlanması ve katılımcıların kolayda örnekleme yöntemiyle seçilmesi nedeniyle sonuçların genellenmesi yanlış değerlendirmelere neden olabilir. Araştırmada öğrencilerin fiziksel aktivite ve sedanter davranış süreleri günlük ortalama olarak belirlenmiş, haftada kaç kez yaptıkları sorulmamıştır. Gelecek araştırmalarda aktivite ve davranışların haftalık sıklığı ile birlikte öğrencilerin beslenme alışkanlıklarının sorgulanması da yararlı olabilir. Araştırmada yaşam kalitesi puanının sadece görsel analog skalası ile değerlendirilmiş olması da bir diğer sınırlılık olarak düşünülmektedir. Gelecek araştırmalarda yaşam kalitesinin çok boyutluluğunu dikkate alan daha kapsamlı ölçeklerin kullanılması yararlı olabilir.

\section{Sonuç ve Öneriler}

Araştırmaya katılan üniversite öğrencilerinin gün içerisinde fiziksel olarak aktif oldukları süre çok az olup, sedanter davranışlar için ayırdıkları süre çok fazladır. Bu yaş döneminde kazanılan fiziksel aktivite alışkanlıklarının ilerleyen yaşlarda sağlık üzerinde yaratacağı faydalar dikkate alınarak, fiziksel aktiviteyi artırmanın yanı sıra sedanter süreyi azaltmaya yönelik fiziksel aktivite, sağlık ve sosyal politikaların geliştirilmesine ve multidisipliner müdahale çalışmalarına ciddi düzeyde ihtiyaç vardır. 
Üniversite öğrencilerinin sedanter davranışlarının çok büyük bir kısmını ekran ve sosyal amaçlı sedanter davranışlar oluşturduğu sonucuna dayanarak, fiziksel aktiviteyi bu davranışlar ile birleştirme ya da değiştirme yönünde müdahale çalışmalarının yararlı olabileceği düşünülmektedir. Bu doğrultuda başta çalışmanın yürütüldüğü üniversite olmak üzere, üniversite öğrencilerinin gidebileceği egzersiz/spor merkezlerinin ekran kullanımı yönünden geliştirilmesi ve öğrencilerin bu konuda bilgilendirilmesi, aile üyeleri ve arkadaşlarla birlikte fiziksel aktiviteye katılımın teşvik edilmesi düşünülebilir. Öğrencilerin fiziksel olarak aktif olmalarının, sedanter davranışların azalmasının sağlayacağı faydaların "ekran"lar üzerinden hazırlanan bilgilendirme ve spotlarla aktarılması da önemli bir araç olabilir.

Son olarak, spesifik olarak kı öğrencileri ve kilolu öğrencileri hedefleyen müdahale çalışmalarının da yararlı olabileceği düşünülmektedir. Alışkanlıkların kuşaklararası aktarımı dikkate alındığında, kız öğrencilerin kazandıkları fiziksel aktivite alışkanlığının hem bireysel, hem de ailevi ve toplumsal faydalarının daha fazla olacağını düşünmek yanlış olmayacaktır. Ayrıca kilolu öğrencilerin ilerleyen yıllarda sağlık açısından daha riskli oldukları düşünüldügüünde, onları hedef alan fiziksel aktivite çalışmalarının daha fazla fayda sağlayacağı öngörülebilir. 
EXTENDED ABSTRACT

\title{
Physical Activity, Sedantery Behaviour and Quality of Life among University Students
}

\begin{abstract}
Atakan Yilmaz
Başkent University

Physical activity is defined as any body movement performed with skeletal muscles that lead to energy consumption above resting level (Caspersen, Powell \& Christenson, 1985). According to World Health Organization data, physical inactivity (lack of physical activity) is the fourth important risk factor among global causes of death (World Health Organization, 2018). The aim of this study was to evaluate the effects of physical activity (PA) and sedentary behavior (SB) on the quality of life of university students.
\end{abstract}

\section{Methods}

The sample of the study was determined as undergraduate students in different departments of a foundation university in Ankara in April 2018 and 400 students were selected by random sampling method and accepted to participate in the study. The questionnaire consisted of the questions related to the socio-demographic characteristics, general health status and daily physical activity and sedentary behavior of the students and the Visual Analogue Scale. In the first part of the questionnaire, socio-demographic information (age, gender, with whom it is experienced, monthly income of the family, etc.), general health assessment (height, weight, general health assessment) and health behaviors (smoking and alcohol use, daily sleep time) 12 questions are included.In order to evaluate Healthrelated Quality of Life in the second part; There is a Visual Analogue Scale in which participants present a value between 0 and 100 to their current health status and marked it on a thermometer-like scale (Ravens-Sieberer et al., 2010). Quality of life scores ranging from 0 to 100 are obtained. The 
third and fourth sections of the questionnaire were prepared by the researchers based on a literature review. In the third chapter, four questions were used to determine the time spent by university students for physical activity, and in the fourth section, 12 questions were used to determine the average time spent by students for sedentary behaviors. In order to adapt the physical activity and sedentary behavior times of the participants to the reality, the total free time remaining outside of the sleep hours was calculated. For this calculation, Sleep Time and Course Duration were removed from the Daily Period. Secondly, the total daily physical activity and sedentary behavior of the participants were calculated by the sum of the responses to the individual expressions. Adapted activity/behavior times of the participants were calculated by proportioning the total free time product calculated by the duration of the behavior they reported to the sum of the squares of each behavior time (Cabanas-Sánchez, 2018). Research data were evaluated by descriptive statistics, Mann-Whitney U test, Kruskal Wallis test and Spearman's correlation coefficient. Of the 400 university students surveyed, $67.3 \%$ were women, with a mean age of $20.49 \pm$ 1.74 years.

\section{Results}

When the actual physical activity duration of the participants was examined, it was determined that the mean time was 2, $00 \pm 1,70$ hours and $17,36 \%$ of the leisure time was physically active. It was determined that males, those living with their nuclear families, those with weak BMI and non-smokers were more physically active in their free time. $(\mathrm{P}<0.05)$. It was determined that the participants were physically active for 2 hours in a day and they were sedentary for an average of 9 hours. The participants adapted to the reality of sedentary behavior and examined the duration of a day, an average of $9,42 \pm 2,28$ hours $(565,38 \pm 136,99 \mathrm{~min})$, free time $82,63 \%$ were sedentary has proved that. The participants adapted to the reality of sedentary behavior and examined the duration of a day, an average of $9,42 \pm 2,28$ hours $(565,38 \pm 136,99 \mathrm{~min})$, free time $82,63 \%$ were sedentary has proved that. When the sedentary behavior times of the participants were examined, it was determined that the mean time was $9.42 \pm 2.28$ hours $(565.38 \pm 136.99 \mathrm{~min})$ and $82.63 \%$ of their leisure time were sedentary. 
When the sedentary behavior distributions of the participants were examined; It was understood that they had sedentary behaviors with $31.6 \%$ screen viewing, $30.6 \%$ social life, $19.1 \%$ education and $18.5 \%$ for other purposes. Quality of life scores of the participants were calculated as $65,59 \pm$ 17,85 . There was a statistically significant relationship between the quality of life scores of the university students and the duration of physically active $(r=0,772, p=0,000)$, and the duration of sedentary behaviors $(r=0,772$, $p=0,000)$. In this study, it was concluded that the duration of physical activity of university students is insufficient for a healthy life, it is important to reduce the time spent for sedentary behaviors especially for screening and social activities. Lastly, it was determined that there was a significant relationship between the duration of physical activity and sedentary behavior of university students and quality of life.

\section{Kaynakça / References}

Aslan, E. ve Yazıcı, A. (2016). Üniversite öğrencilerinde internet bağımlılı̆̆ı ve ilişkili sosyodemografik faktörler. Klinik Psikiyatri Dergisi, 19(3), 109-117.

Balboa-Castillo, T., León-Muñoz, L.M., Graciani, A., Rodríguez-Artalejo, F. ve Guallar-Castillón, P. (2011). Longitudinal association of physical activity and sedentary behavior during leisure time with health-related quality of life in community-dwelling older adults. Health and quality of life outcomes, 9(1), 47-57.

Biswas, A., Oh, P.I., Faulkner, G.E., Bajaj, R.R., Silver, M.A., Mitchell, M.S. ve Alter, D.A. (2015). Sedentary time and Its association with risk for disease incidence, mortality, and hospitalization in adults: a systematic review and Meta-analysis. Annals of Internal Medicine, 162, 123-132. doi: 10.7326/M14-1651.

Cabanas-Sánchez, V., Martínez-Gómez, D., Esteban-Cornejo, I., CastroPiñero, J., Conde-Caveda, J. ve Veiga, Ó.L. (2018). Reliability and validity of the youth leisure-time sedentary behavior questionnaire (YLSBQ). Journal of science and medicine in sport, 21(1), 69-74.

Caspersen, C.J., Powell, K.E., ve Christenson, G.M. (1985). Physical activity, exercise, and physical fitness: Definitions and distinctions for health-related research. Public health reports, 100 (2), 126-131. 
Cengiz, C., İnce, M.L. ve Çiçek, Ş. (2009). Üniversite öğrencilerinin fiziksel aktivite düzeyleri ve fiziksel aktivite tercihleri. Gazi Beden Eğitimi ve Spor Bilimleri Dergisi, 14(2), 23-32.

Cicek, G. (2018). Quality of life and physical activity among university students. Universal Journal of Educational Research, 6(6), 1141-1148.

Clemente, F.M., Martins, F.M.L., Nikolaidis, P.T. ve Mendes, R.S. (2017). Association between physical activity patterns and anthropometric characteristics of adults: An issue of public health? Biomedical Human Kinetics, 9(1), 124-132.

Çavuş, S., Ayhan, B., Tuncer, M. (2016). Bilgisayar oyunları ve bağımlılık: üniversite öğrencileri üzerine bir alan araştırması. İletişim Kuram ve Araştırma Dergisi, 43, 265-289.

Deliens, T., Deforche, B., De Bourdeaudhuij, I. ve Clarys, P. (2015). Determinants of physical activity and sedentary behaviour in university students: a qualitative study using focus group discussions. BMC Public Health, 15(1), 201-210.

Ergül, O.K. ve Çamlıyer, H. (2017). 12-14 yaş grubu ergenlerde ders dışı etkinlikler ve egzersiz kapsamında uygulanan fiziksel aktivite programinın ilköğretim öğrencilerinin yaşam kalitesi üzerindeki etkileri. Dünya Spor Bilimleri Araştırmaları Kongresi, 23 - 26 Kasım 2017, Manisa / Türkiye.

Eruzun, C. (2017). Kadınların spor etkinliklerine katılmalarının boş zaman tatmini ve yaşam kalitesine etkilerinin araştırılması: B-fit spor merkezleri üyeleri örneği. Yüksek lisans Tezi, Bartın Üniversitesi, Eğitim Bilimleri Enstitüsü, Bartın.

Fernandes, R.A. ve Zanesco, A. (2010). Early physical activity promotes lower prevalence of chronic diseases in adulthood. Hypertension Research: Official Journal of the Japanese Society of Hypertension, 33(9), 926-931. doi:10.1038/hr.2010.106.

George, S.M., Alfano, C.M., Groves, J., Karabulut, Z., Haman, K.L., Murphy, B.A. ve Matthews, C.E. (2014). Objectively measured sedentary time is related to quality of life among cancer survivors. PLoS One, 9: e87937. doi: 10.1371/journal.pone.0087937. 
Guallar-Castillón, P., Bayán-Bravo, A., León-Muñoz, L.M., Balboa-Castillo, T., López-García, E., Gutierrez-Fisac, J.L. ve Rodríguez-Artalejo, F. (2014). The association of major patterns of physical activity, sedentary behavior and sleep with health-related quality of life: A cohort study. Preventive medicine, 67, 248-254.

Herman, K.M., Hopman, W.M. ve Sabiston, C.M. (2015). Physical activity, screen time and self-rated health and mental health in Canadian adolescents. Preventive medicine, 73, 112-116.

Joseph, R.P., Royse, K.E., Benitez, T.J. ve Pekmezi, D.W. (2014). Physical activity and quality of life among university students: Exploring self-efficacy, self-esteem, and affect as potential mediators. Quality of life research, 23(2), 659-667.

Kolt, G.S., George, E.S., Rebar, A.L., Duncan, M.J., Vandelanotte, C., Caperchione, C.M., et al. (2017). Associations between quality of life and duration and frequency of physical activity and sedentary behaviour: Baseline findings from the WALK 2.0 randomised controlled trial. PloS one, 12(6), e0180072.

Kuyucu, M. (2017). Gençlerde akıllı telefon kullanımı ve akıllı telefon bağımlılığ1 sorunsalı: "Akıllı telefon (kolik)" üniversite gençliği. Global Media Journal, 7(14), 328-359.

Lapa, T.Y., Korkmaz, N.H. (2017). Fiziksel aktivite düzeyinin pozitif ve negatif duygu durumuna etkisinin cinsiyete göre karşılaştırılması: Akdeniz ve Uludağ Üniversiteleri örneği. Journal of Human Sciences, 14(4), 3177-3187.

Lindsay, D.B., Devine, S., Sealey, R.M., Leicht, A.S. (2016). Time kinetics of physical activity, sitting, and quality of life measures within a regional workplace: A cross-sectional analysis. BMC public health; 16(1), 786-795.

Malina, R.M. (2001). Physical activity and fitness: Pathways from childhood to adulthood. American Journal of Human Biology: The Official Journal of the Human Biology Council, 13(2), 162-172.

Meneguci, J., Sasaki, J.E., Santos, A., Scatena, L.M., Damião, R. (2015). Sitting time and quality of life in older adults: A population-based study. Journal of Physical Activity and Health; 12(11), 1513-1529. doi: 10.1123/jpah.2014-0233. 
Nelson, C.C., Wagner, G.R., Caban-Martinez, A.J., Buxton, O.M., Kenwood, C.T., ve Sabbath, E.L.(2014). Physical activity and body mass index: the contribution of age and workplace characteristics. American journal of preventive medicine, 46(3), 42-51.

Noyan, C.O., Enez Darçın, A., Nurmedov, S., Yılmaz, O. ve Dilbaz, N. (2015). Akıllı telefon bağımlılı̆̆ı ölçeğinin kısa formunun üniversite öğrencilerinde Türkçe geçerlilik ve güvenilirlik çalışması. Anadolu Psikiyatri Dergisi, 16, 73-81.

Omorou, A.Y., Langlois, J., Lecomte, E., Briançon, S. ve Vuillemin, A. (2016). Cumulative and bidirectional association of physical activity and sedentary behaviour with health-related quality of life in adolescents. Quality of Life Research, 25(5), 1169-1178.

Omorou, A.Y., Vuillemin, A., Menai, M., Latarche, C., Kesse-Guyot, E., Galan, P., Hercberg, S., Oppert, J.M. ve Briançon, S. (2016). 10-year cumulative and bidirectional associations of domain-specific physical activity and sedentary behaviour with health-related quality of life in French adults: Results from the SU.VI.MAX studies. Preventive Medicine, 88, 66-72.doi: 10.1016/j.ypmed.2016.03.023.

Owen, N., Healy, G.N., Matthews, C.E. ve Dunstan, D.W. (2010) Too much sitting: the population-health science of sedentary behavior. Exercise and Sport Sciences Reviews, 38, 105-113.

Özdemir, O., Özşaker, M., Ersöz, G. (2016). Serbest zaman etkinliği olarak egzersiz yapan üniversite öğrencilerinde güdüsel yönelim ve psikolojik iyi oluş ilişkisi. Turkish International Journal of Special Education and Guidance \& Counselling, 5(2),13-22.

Peterson, N.E., Sirard, J.R., Kulbok, P.A., DeBoer, M.D. ve Erickson, J.M. (2018). Sedentary behavior and physical activity of young adult university students. Research in nursing and health, 41(1), 30-38.

Ravens-Sieberer, U., Wille, N., Badia, X., Bonsel, G., Burström, K., Cavrini, G., et al. (2010). Feasibility, reliability, and validity of the EQ-5DY: results from a multinational study. Quality of life research, 19(6), 887-897.

Sabbağ, Ç., Aksoy, E. (2011). Üniversite öğrencileri ve çalışanların boş zaman etkinlikleri: Adıyaman örneği. Mehmet Akif Ersoy Üniversitesi Sosyal Bilimler Enstitüsü Dergisi, 4, 10-23. 
Sağlam, Y. ve Yılmaz, G. (2017). Evaluation of physical activity levels and quality of life of teachers. Acta Kinesiologica, 11 (1), 25-32.

Sağlık Bakanlığı. (2015). Türkiye fiziksel aktivite rehberi 2014. Türkiye Halk Sağlığı Kurumu, Sağlık Bakanlığı Yayın No: 940, Ankara.

Sedentary Behaviour Research Network (2012). Letter to the editor: Standardized use of the terms "sedentary" and "sedentary behaviours. Applied Physiology, Nutrition, and Metabolism, 37, 540-542. doi: 10.1139/h2012-024.

Taricco, M., Dallolio, L., Calugi, S., Rucci, P., Fugazzaro, S., Stuart, M., Pillastrini, P., Fantini, M.P., Esercizio Fisico di Gruppo/2009 Investigators. (2014). Impact of adapted physical activity and therapeutic patient education on functioning and quality of life in patients with postacute strokes. Neurorehabilitation and Neural Repair, 28: 719-728. doi: 10.1177/1545968314523837.

Tekkanat, Ç. (2008). Öğretmenlik bölümünde okuyan öğrencilerde yaşam kalitesi ve fiziksel aktivite düzeyleri. Yüksek lisans Tezi, Pamukkale Üniversitesi Sağlık Bilimleri Enstitüsü, Denizli.

Tözün, M., Sözmen, M.K. ve Babaoğlu, A.B. (2017). Türkiye'nin batısında bir üniversite'nin sağlık ile ilişkili okullarında beslenme alışkanlıkları ve bunun obezite, fizik aktivite ve yaşam kalitesi ile ilişkisi. Türk Dünyası Uygulama Ve Araştırma Merkezi Halk Sağh̆ğı Dergisi, 2(1), 1-16.

Tremblay, M.S., Aubert, S., Barnes, J.D., Saunders, T.J., Carson, V. ve Latimer-Cheung, A.E (2017). Sedentary behavior research network (SBRN)-terminology consensus project process and outcome. International Journal of Behavioral Nutrition and Physical Activity, 14(1), 75-92. doi: 10.1186/s12966-017-0525-8.

Tremblay, M.S., Colley, R.C., Saunders, T.J., Healy, G.N. ve Owen, N. (2010). Physiological and health implications of a sedentary lifestyle. Applied Physiology, Nutrition, and Metabolism,35, 725-40.

Vagetti, G.C., Barbosa Filho, V.C., Moreira, N.B., de Oliveira, V., Mazzardo, O. ve de Campos, W. (2014). Association between physical activity and quality of life in the elderly: a systematic review, 20002012. Revista Brasileira de Psiquiatria, 36, 76-88. doi:10.1590/15164446-2012-0895. 
Üniversite Öğrencilerinde Fiziksel Aktivite, Sedanter Süre ve Yaşam Kalitesi İlişkisinin Değerlendirilmesi

World Health Organization (2018). Global action plan on physical activity 2018-2030: More active people for a healthier world. Geneva: World Health Organization. Available from: http://apps.who.int/iris/bitstream/handle/10665/272722/9789241514187-eng.pdf

Wu, X.Y., Han, L.H., Zhang, J.H., Luo, S., Hu, J.W. ve Sun, K. (2017). The influence of physical activity, sedentary behavior on health-related quality of life among the general population of children and adolescents: A systematic review. PloS one, 12(11): e0187668. doi: 10.1371/journal.pone.0187668.

\section{Kaynakça Bilgisi / Citation Information}

Yılmaz, A. (2019). Üniversite öğrencilerinde fiziksel aktivite, sedanter süre ve yaşam kalitesi ilişkisinin değerlendirilmesi. OPUS-Uluslararası Toplum Araştırmaları Dergisi, 10(17), 1433-1453. DOI: 10.26466/opus.532283 